\title{
Impact of natural ultraviolet radiation on rates of photosynthesis and on specific marine phytoplankton species
}

\author{
E. Walter Helbling ${ }^{1}$, Virginia Villafañe ${ }^{1}$, Martha Ferrario ${ }^{2}$, Osmund Holm-Hansen ${ }^{1}$ \\ ${ }^{1}$ Polar Research Program, Scripps Institution of Oceanography, University of California, San Diego, La Jolla, \\ California 92093-0202, USA \\ ${ }^{2}$ Facultad de Ciencias Naturales y Museo, Universidad Nacional de La Plata, (1900) La Plata, Buenos Aires, Argentina
}

\begin{abstract}
Natural phytoplankton populations from both Antarctic and tropical waters were exposed to solar radiation to determine the effects of ultraviolet radiation (UVR) on rates of photosynthesis. Radiation in the UV-A region (320 to $400 \mathrm{~nm}$ ) was responsible for over $50 \%$ of the total inhibition due to UVR, with less than $50 \%$ due to UV-B (280 to $320 \mathrm{~nm})$. Wavelengths $<305 \mathrm{~nm}$, which is the spectral region most enhanced under conditions of low ozone concentrations in the atmosphere, accounted for only 15 to $20 \%$ of the total inhibition due to UV-B radiation. Under high-light conditions on sunny days, photosynthetic rates were increased 200 to $300 \%$ by screening off all UVR below $378 \mathrm{~nm}$. When the average UVR ( 295 to $385 \mathrm{~nm}$ ) during the incubation period was below a threshold value of 5 to $10 \mathrm{~W} \mathrm{~m}^{-2}$, there was no significant depression of photosynthetic rates. Microscopic examinations of a phytoplankton population which was allowed to grow for $5 \mathrm{~d}$ under high solar irradiance indicated that UVR is more inhibitory to microplankton than to nanoplankton, and that it induced the formation of resting spores in diatom species of the genus Chaetoceros. Phytoplankton from tropical waters showed marked resistance to UVR as compared to Antarctic phytoplankton. Under the highest light conditions an increase in photosynthetic rates of 10 to $20 \%$ was recorded in some experiments by screening off all UVR $<378 \mathrm{~nm}$, but when data from all experiments with samples from surface waters in the tropics were analyzed, there was no significant difference between samples with or without natural solar UVR. Phytoplankton samples from below the pycnocline in tropical waters, however, were very sensitive to solar radiation, suggesting that the resistance shown by phytoplankton from surface waters reflects a photoadaptive process.
\end{abstract}

\section{INTRODUCTION}

Since discovery of the ozone hole over Antarctica in the mid-1980's there has been much interest and concern expressed regarding the impact of increased ultraviolet radiation (UVR) on the Antarctic marine ecosystem (El-Sayed 1988, Gribbin 1988, Voytek 1989). The seasonal loss of ozone over Antarctica, which has been documented since 1957 (Farman et al. 1985), apparently is becoming progressively more severe with time. The 1990 ozone hole, which was equal in magnitude to the record 1987 ozone hole, started to form in August and persisted for an unusually long period, with low ozone values being recorded throughout the month of December (Newman et al. 1991).

Recent data indicate that the loss of ozone in the stratosphere is not limited to the southern hemisphere, but is a world-wide phenomenon. NASA scientists (Stolarski et al. 1991) have shown that ozone levels between $65^{\circ} \mathrm{S}$ and $65^{\circ} \mathrm{N}$ have decreased ca $3 \%$ during the past decade, with the ozone loss close to zero at the equator and increasing toward both poles. At $50^{\circ} \mathrm{N}$ the loss of ozone over the same time period was about $5 \%$. Concern over the impact of enhanced UVR on aquatic ecosystems thus is not a problem limited to the south polar region, but has world-wide significance.

Decreased ozone concentrations in the stratosphere will result predominantly in an increase of UV-B (280 to $320 \mathrm{~nm}$ ) radiation incident upon the earth. This increase is relatively slight at $320 \mathrm{~nm}$, but increases dramatically (as compared to a normal ozone day) at the shorter UV-B wavelengths (Lubin et al. 1989, Lubin \& Frederick 1991). In order to understand the possible impact on phytoplankton of ozone-related enhanced levels of UVR in the southern ocean (all regions south 
of the Polar Front) and elsewhere, it is necessary to increase our understanding of the biological significance of both UV-B and UV-A (320 to $400 \mathrm{~nm}$ ), and also to determine the action spectrum of UVR-induced deleterious effects on biological processes.

In this paper we are primarily concerned with the following questions or problems: (1) What is the dose-response relationship between UVR and the degree of inhibition of photosynthesis? (2) What spectral regions of UVR are most important in regard to decreasing photosynthetic activity? (3) Are Antarctic phytoplankton more sensitive than tropical phytoplankton to UVR? The basis for this concern is that Antarctic phytoplankton historically have been exposed to lower levels of UVR than tropical phytoplankton, and hence it is generally assumed that phytoplankton in the southern ocean are genetically adapted to relatively low UVR stress and that any significant increase in UV-B radiation might have calamitous results. (4) Do natural levels of UVR have significant effects on species composition of the phytoplankton crop or on initiation of reproductive siages?

\section{MATERIALS AND METHODS}

Area and time of work. Studies in Antarctica were done either at Palmer Station or on board RV 'Polar Duke' in 1988 and 1989 (Fig. 1, Inset B) or on RV 'Surveyor' during January-March of 1991 (Fig. 1, Inset A). The response of tropical phytoplankton to UVR was studied during the transit of RV 'Surveyor' from Valparaiso, Chile, to San Diego, California, USA, in March-April of 1991 (Fig. 1).
Sampling protocol. Studies at Palmer Station were done with water samples from Arthur Harbor obtained either with a clean plastic bucket or with a $5.0 \mathrm{l}$ PVC Niskin bottle equipped with a teflon-covered stainless steel spring. Water samples for shipboard studies were obtained at 10 depths $(0$ to $100 \mathrm{~m}$ ) with $10 \mathrm{l}$ Niskin bottles (teflon-covered springs) attached to a profiling rosette (General Oceanics) equipped with (1) sensors for pressure, temperature, and conductivity (Sea Bird, Inc., model SBE-9), and (2) a light sensor (QSP-200L, Biospherical Instruments, Inc.) for photosynthetically available radiation (PAR; 400 to $700 \mathrm{~nm}$ ). Sensitivity to UVR was usually tested with samples from just 1 or 2 depths, whereas samples for other measurements (e.g. chlorophyll a [chl a] and floristics) were taken from all 10 depths.

Incubation of samples. Sample containers (made from quartz or pyrex) were either round vessels $(250 \mathrm{ml}$ capacity) equipped with a hemi-spherical groundglass joint, or tubes (60 or $100 \mathrm{ml}$ capacity) with ground-glass joints. Any one experiment used either the round vessels or the tubes, but not both. Long-term cuiture experiments utilized round Chemglass vesseis (1000 ml capacity) with ground-glass joints. The sample vessels were wrapped with various kinds of cut-off filters to remove various spectral portions of solar radiation. The absorption characteristics of all filters and glassware used in our experiments were determined in a split-beam UV-visible spectrophotometer (Perkin-Elmer, model Lambda 4A) and are shown in Fig. 2. Cellulose triacetate film with $50 \%$ transmission at $297 \mathrm{~nm}$ was also used in a few experiments. The absorption curve for this film is not included in Fig. 2 as it almost overlaps the curve for absorption by Chemglass.

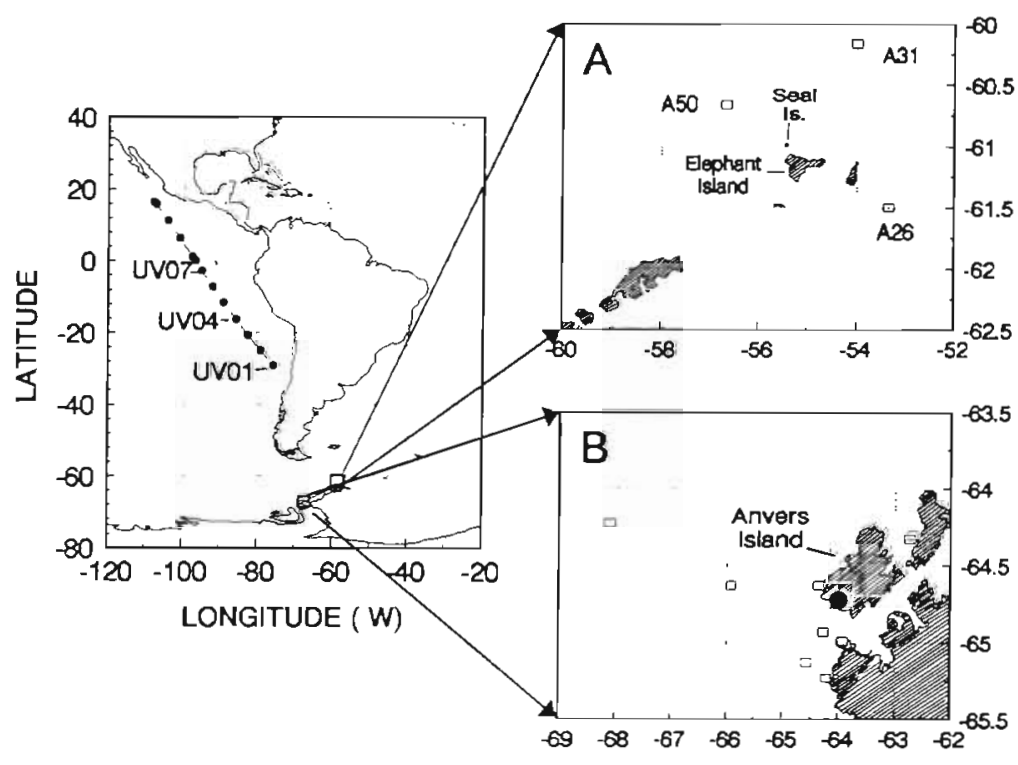

Fig. 1 Station locations in tropical waters during a transect across the equator (March 28 to April 12, 1991) and in Antarctica during January 1 to March 17, 1991 (Inset A) and during October-November of 1988 and 1989 (Inset $\mathrm{B}_{i}$ : location of Palmer Station 


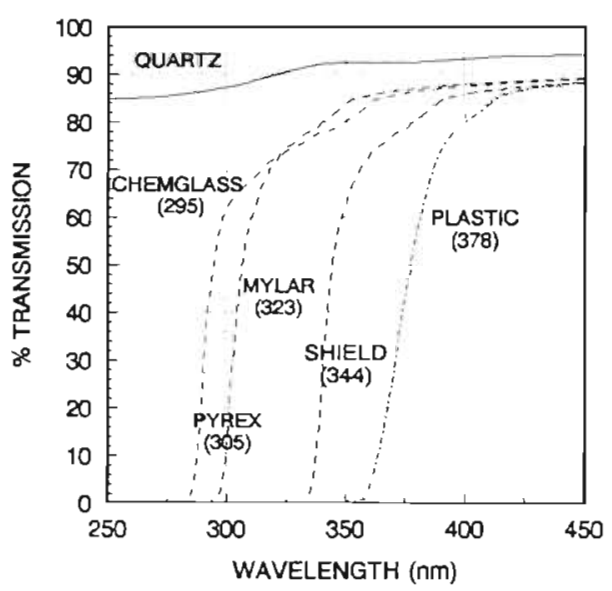

Fig. 2. Absorption characteristics of various materials and filters used in UVR experiments. Numbers in parentheses indicate wavelength in nanometers corresponding to $50 \%$ transmission. The plastic filter is a flexible film $0.27 \mathrm{~mm}$ in thickness; the mylar film is $0.10 \mathrm{~mm}$ thick; the shield is plexiglass of $3.17 \mathrm{~mm}$ thickness

Water samples were dispensed into the vessels, either in duplicate or triplicate for any one treatment, and either 5.0 or $10.0 \mu \mathrm{Ci}(0.185$ or $0.37 \mathrm{MBq})$ of ${ }^{14} \mathrm{C}$ bicarbonate was added. The sample vessels were then secured in an incubator with flowing surface sea water for temperature control. The incubators used did not shade any of the samples as the incubators were large relative to the size of the sample vessels, and the vessels were close to the top of the incubator and just under the water level. During some experiments the incubator was covered with a neutral density screen (gray plastic mesh) to attenuate solar radiation to all the samples. After 6 to $10 \mathrm{~h}$ incubation centered around local noon, the samples were filtered through Whatman GF/F glass fiber filters (25 mm) and inserted into scintillation vials. After exposure of the filters to fumes from concentrated $\mathrm{HCl}$ overnight, the filters were dried, and the incorporated radiocarbon was measured by standard liquid scintillation procedures. More than 250 samples from Antarctica and more than 150 samples from tropical waters were processed in this way.

Cultures of Antarctic phytoplankton. Water samples collected close to Seal Island (Fig. 1, Inset A) were incubated within $30 \mathrm{~min}$ of collection either in (1) 2 l acid-washed polycarbonate bottles in a refrigerator $\left(0\right.$ to $4{ }^{\circ} \mathrm{C}$ ) equipped with daylight fluorescent lamps providing $150 \mu$ Einsteins $\mathrm{m}^{-2} \mathrm{~s}^{-1}$ to the samples, or (2) in 11 round Chemglass vessels in a deck incubator with flowing surface seawater and exposed to natural sunlight. The cultures in the illuminated refrigerator were used in later experiments when the ship was in transit through tropical waters. Six Chemglass vessels were used in each experiment, with the control vessels having no filter, and duplicate vessels being screened with either Mylar or Plastic. Chl a concentrations in these cultures were measured every day by withdrawing 20 to $50 \mathrm{ml}$ of sample. A $50 \mathrm{ml}$ sample was withdrawn every 2 nd day and preserved in boratebuffered formalin for later microscopic observations.

Measurement of solar irradiation. Incident solar PAR (400 to $700 \mathrm{~nm}$ ) was recorded continuously with a hemi-spherical irradiance sensor (BSI Inc., model \#QSR-240). Total ultraviolet radiation (295 to $385 \mathrm{~nm}$ ) was continuously recorded with an Eppley Radiometer (model TUVR), while total radiation (285 to $2800 \mathrm{~nm}$ ) was measured with an Eppley spectral pyranometer (model PSP). The signals from these instruments were averaged over $1 \mathrm{~min}$ every $10 \mathrm{~min}$ by a data acquisition system (Hewlett-Packard, model 3421-A) and recorded in an AT-386 computer.

Integrated PAR incident upon our samples was also measured with a battery-operated integrating quantum scalar irradiance meter (BSI Inc., model QSI-140) which was placed in or next to the sample incubator. Instantaneous measurements of PAR were done with a quantum scalar irradiance meter (BSI Inc., model QSL100), which was used for measuring the attenuation of our neutral density filters and also for measuring the irradiance within the sample bottles. Attenuation of PAR in the upper water column was measured with a cosine sensor (BSI Inc., model \#QCP-200L) attached to the profiling rosette

Chlorophyll a. Water samples $(100 \mathrm{ml}$ or less) were filtered onto glass fiber filters (Whatman GF/F, $25 \mathrm{~mm}$ ), extracted in absolute methanol (Holm-Hansen \& Riemann 1978), and the fluorescence measured in a Turner Designs fluorometer (Holm-Hansen et al. 1965). The instrument was calibrated against purified chl $a$, and the stability of the instrument measured every day by use of a coproporphyrin standard.

Floristic analyses. Water samples were routinely preserved both with Lugol's iodine solution and with buffered formalin and returned to the Scripps Institution for analysis. Selected samples (both fresh and preserved) were examined on board ship using a compound microscope equipped with an epifluorescence unit. For inverted microscope observations, a drop of Rose Bengal was added to each sample (10 to $100 \mathrm{ml})$ before the sample was allowed to settle for 24 to $48 \mathrm{~h}$. Standard inverted microscope techniques (Utermöhl 1958, Reid 1983) were then used to record species composition and to determine cell numbers and dimensions so that cell biovolumes and biomass (expressed in cellular carbon) could be estimated using appropriate equations (Strathmann 1967. Hitchcock 1983). Cells which appeared empty or did not stain with Rose Bengal were considered to be dead. 


\section{RESULTS}

Only representative experiments are described in detail in the following sections. All results, however, have been used in the statistical analyses of the data

\section{Antarctic water samples}

Data in Fig. 3 show that screening off the shorter UV-B wavelengths with pyrex $(<305 \mathrm{~nm}$ ) increased assimilation numbers of Antarctic phytoplankton by relatively small amounts, whereas screening off most UV-B and UV-A radiation with the plastic filter increased photosynthetic rates very significantly. The percent enhancement in photosynthetic rates caused by removal of most of the UVR (plastic filter) was maximal (304\%) at the highest light level used (Fig. 3A) and decreased progressively with decreasing light levels, so that at the lowest light level used (Fig. 3D), the enhancement was only $50 \%$. The data also show that the assimilation numbers were all very low (Fig. 3A) at the highest iight leveis, but acnieved fairly normal values in Fig. 3B (for the plastic treatments only) and in Fig. 3C (for the samples in quartz and pyrex). This indicates that while most of the photoinhibition of photosynthesis was due to UVR, the high levels of PAR during the experiment were partially responsible for the low assimilation numbers.
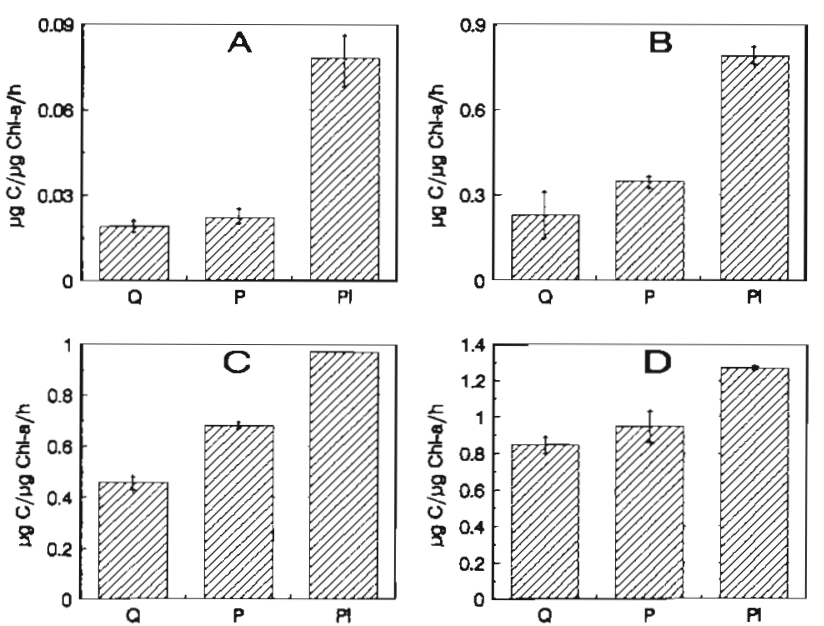

Fig. 3. Photosynthetic rates (expressed as assimilation numbers) of Antarctic phytoplankton as influenced by spectral irradiance incident upon the phytoplankton ( $Q$ : quartz. vessels; P: pyrex vessels; Pl: plastic filter) and by decreasing total irradiance with neutral density screens (mean PAR irradiance levels in (A), (B), (C), and (D) were 2700, 1350, 675, and $338 \mu$ Einsteins $\mathrm{m}^{-2} \mathrm{~s}^{-1}$, respectively]. Water samples were from $5 \mathrm{~m}$ depth in Arthur Harbor (Palmer Station), December 5, 1988. Initial chl a concentration in all samples was $4.1 \mu \mathrm{g} \mathrm{l}^{-1}$ Vertical lines indicate minimum and maximum values
It should be noted that the day of this experiment at Palmer Station was exceptionally clear and sunny, and the incident irradiation was enhanced considerably by reflection from the surrounding glaciers and snowfields.

The photosynthetic response to removal of spectral regions of UVR varies depending upon the species composition of the crop and the previous light history of the phytoplankton. Phytoplankton from Stn A26 which were incubated in pyrex showed $21 \%$ enhancement in the rate of ${ }^{14} \mathrm{C}$ incorporation as compared to samples in quartz bottles, whereas those samples in which UV-B was screened out by mylar showed $82 \%$ enhancement and those screened by plastic showed
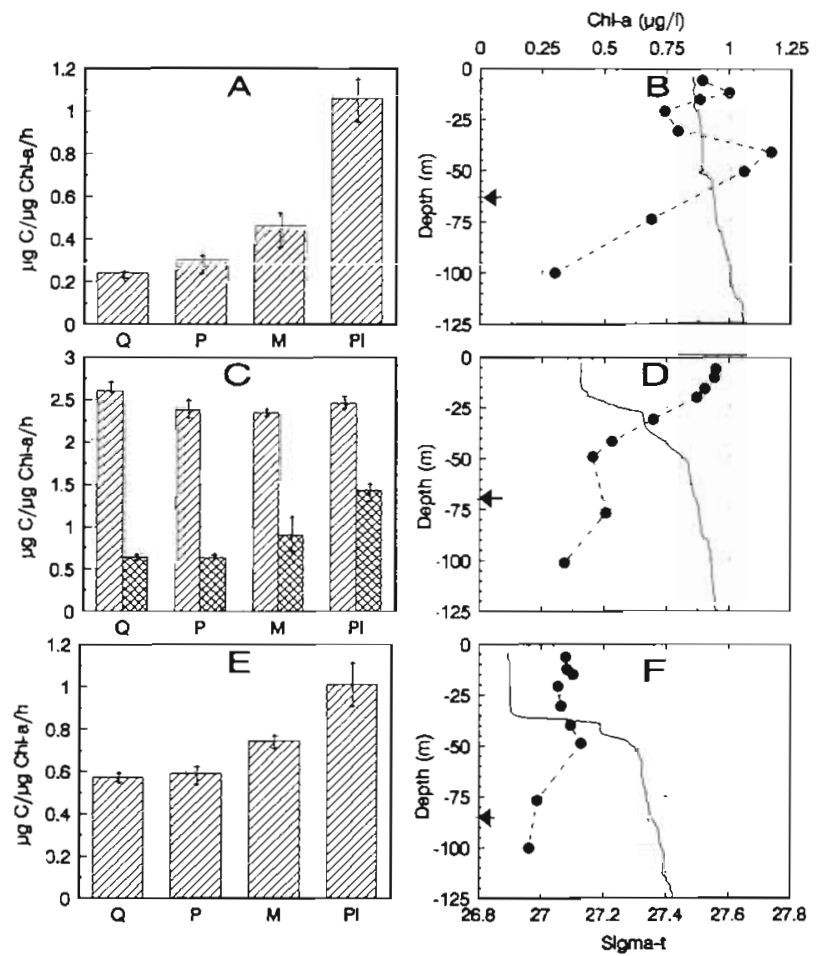

Fig. 4. Photosensitivity to UVR of Antarctic phytoplankton when sampled from different locations or depths in the water column. Data in (A), (C), and (E) show photosynthetic assimilation numbers as a function of spectral irradiance incident upon the phytoplankton $(\mathrm{Q}=$ quartz; $\mathrm{P}=$ pyrex; $\mathrm{M}=$ mylar; $\mathrm{Pl}=$ plastic filter). Data in $(B),(D)$, and $(F)$ show profiles of water column density (sigma-t; continuous line), chl a concentrations (solid dots and dashed line), and depth of $1 \%$ incident radiation (solid arrow). (A), (B) Water sample from $5 \mathrm{~m}$ at Stn A26 (January 27, 1991), incubated under mean irradiance of $2055 \mu$ Einsteins $\mathrm{m}^{-2} \mathrm{~s}^{-1}$ for PAR and $19.9 \mathrm{~W} \mathrm{~m}^{-2}$ for total UVR. (C), (D) Water samples from $15 \mathrm{~m}$ (hatched bar) and $75 \mathrm{~m}$ (cross hatched bar) at Str A31 (January 28, 1991), incubated under mean surface PAR of $755 \mu$ Einsteins $\mathrm{m}^{-2} \mathrm{~s}^{-1}$ and mean total UVR of $8.4 \mathrm{~W} \mathrm{~m}^{-2}$. (E), (F) Water sample from $10 \mathrm{~m}$ at Stn A50 (February 1, 1991), incubated at mean PAR of $2044 \mu \mathrm{E} \mathrm{m}^{-2} \mathrm{~s}^{-1}$ and mean total UVR of $18.2 \mathrm{~W} \mathrm{~m}^{-2}$. Vertical lines indicate minimum and maximum values 
$350 \%$ enhancement (Fig. 4A; note that the day of incubation was bright and sunny). There was no distinct upper mixed layer (UML) at this station, and the slight increase in water density with depth (Fig. 4B) suggests that the phytoplankton might be mixing deeply and hence would be dark-adapted. Cryptophytes, ranging from 10 to $15 \mu \mathrm{m}$ in size, accounted for more than $85 \%$ of the total phytoplankton carbon at this station. Smaller flagellates ( 2 to $5 \mu \mathrm{m}$ ) and dinoflagellates accounted for most of the remainder of the phytoplankton crop

Stn A31 (Fig. 4D) showed a fairly shallow and relatively uniform UML of ca $20 \mathrm{~m}$ depth. Phytoplankton from within this UML showed no enhancement of photosynthetic rates by removal of UVR (note that day of incubation was overcast, with little sunlight), whereas samples from $75 \mathrm{~m}$ depth showed $40 \%$ enhancement when screened by mylar, and $120 \%$ for the samples screened by plastic (Fig. 4C). The phytoplankton crop at this station was dominated by dinoflagellates, which accounted for $50 \%$ of the total phytoplankton carbon. Small flagellates (5 to $20 \mu \mathrm{m}$ ) and various diatoms (e.g. Corethron criophilum and Rhizosolenia spp.) accounted for most of the remainder.

The water column at Stn A50 had a deep and homogeneous UML of ca $35 \mathrm{~m}$ (Fig 4F). Samples were incubated on a sunny day, and the enhancement in photosynthetic rates as compared to the samples in quartz vessels were $3 \%$ for pyrex, $30 \%$ for mylar, and $76 \%$ for plastic (Fig. 4E). Diatoms accounted for more than $80 \%$ of the phytoplankton carbon in these samples, with a predominance of small pennate forms $(<15 \mu \mathrm{m})$ such as Nitzschia 'nana' (Nitzschia species from the Fragilariopsis section). Centric diatoms, mostly Rhizosolenia hebetata f. semispina, were also present.

Data in Fig. 5 summarize all our values showing the relationship between percent enhancement in photosynthetic rates when various spectral regions of the UVR are selectively removed and the total UVR flux incident upon the samples in quartz vessels. It is seen that for all 3 filters used (pyrex, mylar, plastic) there appears to be a threshold between 5 to $10 \mathrm{~W} \mathrm{~m}^{-2}$, below which there is little or no enhancement. Above this value the percent enhancement increases, reaching maximal values of ca $20 \%, 100 \%$, and $340 \%$ for pyrex, mylar, and plastic, respectively, when total UVR fluxes are about $30 \mathrm{~W} \mathrm{~m}^{-2}$.

Antarctic cultures. The above experiments were all short in duration ( 6 to $10 \mathrm{~h}$ ). We also determined possible long-term effects of UVR on natural assemblages allowed to grow until nutrients were depleted. Data in Fig. 6A show that there was no effect on growth rates when solar radiation was screened through mylar or

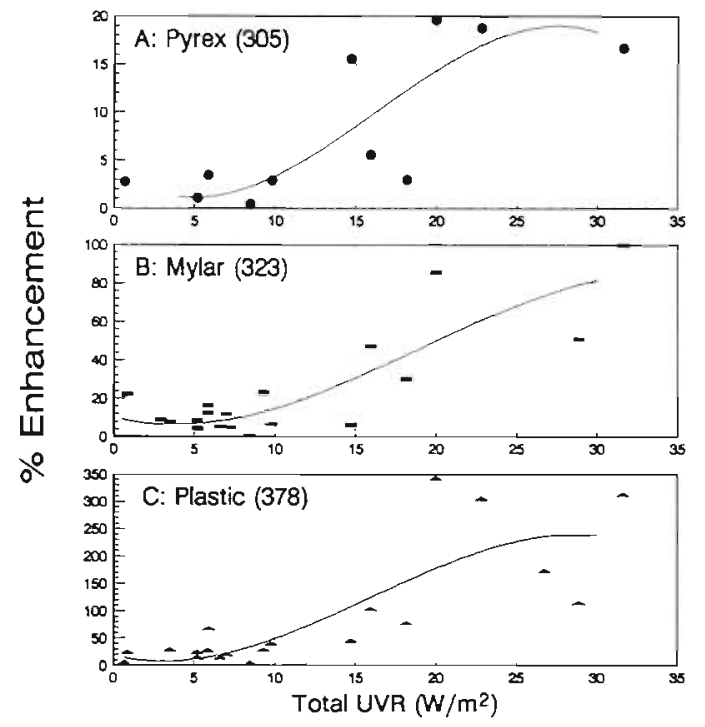

Fig. 5. Percentage of enhancement of photosynthetic rates as a function of mean incubation values of UVR incident upon the samples in quartz vessels and when various spectral regions of UVR are removed by pyrex, mylar, or plastic filters. Data from 1988, 1989, and 1991 Note the different ordinate values in $(A),(B)$, and $(C)$. Lines through data points were computer drawn, using a third degree polynomial function

plastic as compared to the controls in Chemglass. Growth in all 3 treatments resulted in over $60 \mu \mathrm{g}$ chl a $\mathrm{l}^{-1}$, with no significant differences in the cultures, either in growth rate or final yield. The weather conditions during this experiment were generally overcast, resulting in low incident solar radiation (Fig. 6B). Total UVR averaged less than $8 \mathrm{~W} \mathrm{~m} \mathrm{~m}^{-2}$, which is within the threshold range noted in Fig. 5. Floristic analyses did not reveal any significant differences in species composition in the different treatments. The phytoplankton crop consisted mainly of diatoms, with the dominant species being Nitzschia 'nana'. Centric diatoms (e.g. Thalassiosira spp. and Rhizosolenia spp.) and flagellates (2 to $5 \mu \mathrm{m}$ ) were also present in significant numbers.

In order to see how this Antarctic phytoplankton crop would respond to the different spectral characteristics of solar radiation at low latitudes, the culture (which had been maintained for 2 wk in the illuminated refrigerator on board ship) was diluted with cold nutrient-rich sea water (from $1000 \mathrm{~m}$ in the Antarctic, which had been filtered through a GF/F glass fiber filter) and dispensed into the Chemglass vessels. These cultures, all of which were incubated in a refrigerated water bath $\left(0\right.$ to $\left.4^{\circ} \mathrm{C}\right)$ and screened with a neutral density filter to attenuate solar radiation to $50 \%$ (Fig. 6D), showed a lag phase of $3 \mathrm{~d}$ (Fig. 6C). All cultures showed good growth during the 4 th day, but during the 5th day the samples in Chemglass vessels 

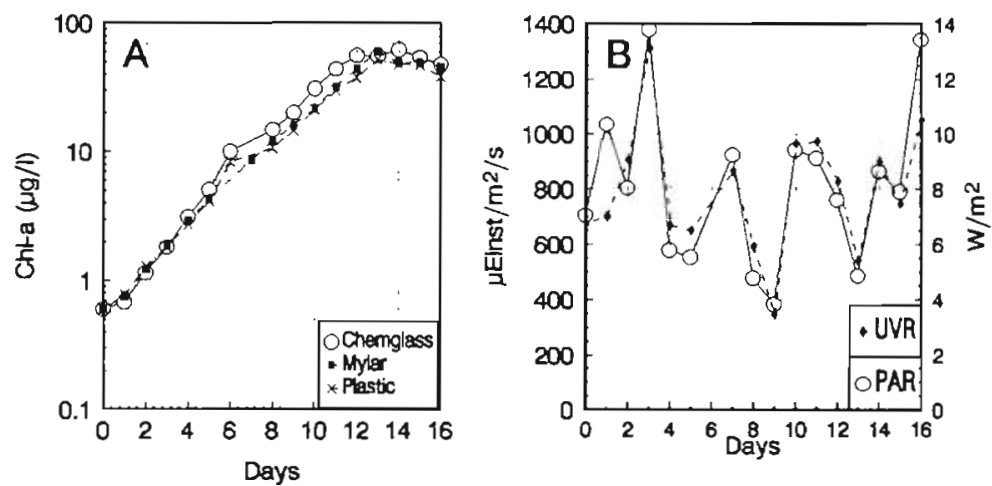

Fig. 6. Growth of a natural phytoplankton population from Antarctic waters (sample from close to Seal Island, just north of Elephant Island) as
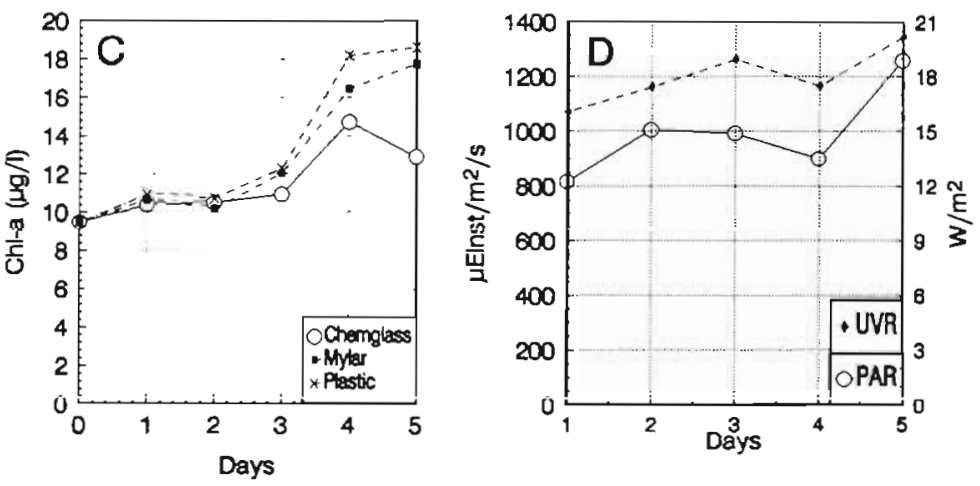
influenced by removal of spectral regions of UVR and by total UVR incident upon the culture. (A) Rate of chl a synthesis from February 19 to March 7, 1991, in vessels screened with mylar or plastic as compared to controls in Chemglass vessels. Each point is the mean value of duplicatcs. (B) Mean irradiance of each day for total UVR and PAR incident upon the cultures. (C) Rate of chl a synthesis in the Antarctic culture maintained in the low-temperature incubator and then exposed to natural solar radiation in tropical waters (March 30 to 4 pril 3, 1991). (D) Mean irradiance of each day for total UVR and PAR incident upon the cultures

decreased in content of chl a. At the end of Day 5 (when the refrigerated water bath failed), the samples screened by mylar or plastic had ca $50 \%$ more chl a (and biomass, as determined by floristic analyses) as compared to the controls.

Microscopic observations at Day 0 of the natural Antarctic phytoplankton assemblage incubated in the Antarctic (Fig. 6A) and in the tropics (Fig. 6C) revealed that the crops were similar in species composition. Observations of samples from this experiment in the tropics showed differences in the phytoplankton composition between treatments. The ratios of nanoplankton/microplankton cell numbers, shown in Fig. 7A, show that filtering off UV-B by mylar enhanced the growth of microplankton more than nanoplankton, and that removal of most UV-A radiation resulted in a further enhancement of microplankton numbers relative to nanoplankton. The decrease in these ratios $(35 \%$ and $37 \%$ for mylar and plastic, respectively, at Day 5) indicates that microplankton cells are more sensitive than nanoplankton to UVR. Our microscopic observations also suggested that some phytoplankton forms, in particular Chaetoceros spp. and Thalassiosira gracilis var. expecta, appeared to show more morphological changes in response to UVR than the rest of the crop. Chaetoceros spp., when incubated in Chemglass vessels without any cut-off filter, showed a high concentration of resting spores as compared to vegetative cells (Fig. 7B). However, removing UV-B with mylar reduced the number of spores formed; removing both UV-B and UV-A with the plastic filter resulted in a further decrease in the rate of spore formation. No spores were seen in the culture at Day 0 . In regard to $T$. gracilis var. expecta, the different irradiation regimes resulted in altering the relative number of vegetative to dead cells (Fig. $7 \mathrm{C}$ ). The culture exposed to the highest UVR flux showed the most dead cells; the culture screened by mylar had fewer dead cells, and the culture screened by plastic had the fewest. The irradiance incident upon these cultures is shown in Fig. 6D.

\section{Tropical phytoplankton}

Effects of natural UVR on photosynthetic activity of tropical phytoplankton from 3 representative stations (see Fig. 1) are shown in Fig. 8. No neutral density screens were used in these experiments as preliminary tests had shown that any enhancement by removing UVR was relatively slight under full solar irradiance, and no enhancement was seen when incident radiation was reduced to $50 \%$ with one neutral density screen. The radiation levels for all the data shown in Fig. 8 are thus very high as compared to previous work with Antarctic samples. There was no enhancement of photosynthetic rates by phytoplankton at Stn UV01 when short UV-B wavelengths 

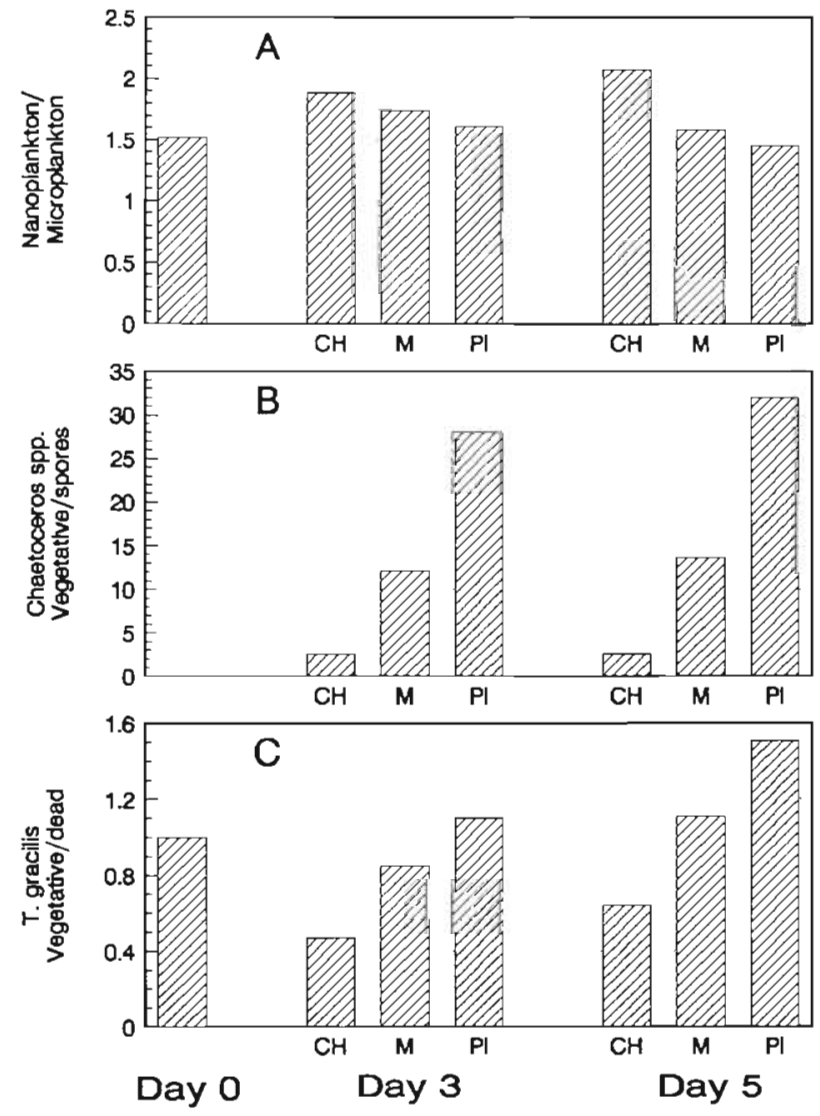

Fig. 7. Changes in cellular characteristics of Antarctic phytoplankton when subjected to different UVR regimes at low latitudes. Controls are in Chemglass ( $\mathrm{CH}$ ); $\mathrm{M}$ : mylar; Pl: plastic filter; day number refers to day shown in Fig. 6C. (A) Ratio of nanoplankton $(<20 \mu \mathrm{m})$ to microplankton $(>20 \mu \mathrm{m})$. (B) Ratio of vegetative cells to spores of the diatom Chaetoceros spp. (C) Ratio of vegetative cells to dead cells of the diatom Thalassiosira gracilis var. expecta. Cells which did not stain with Rose Bengal were considered to be dead

were absorbed by pyrex glass (Fig. 8A), but there were small increases in radiocarbon incorporation with both mylar and plastic treatments (18\% and $17 \%$, respectively). There was a deep UML at this station down to about $55 \mathrm{~m}$ (Fig. 8B), but with a slight increase in water density at ca $30 \mathrm{~m}$ depth. The chl a profile was fairly uniform down to $30 \mathrm{~m}$, suggesting that the phytoplankton sampled from $5 \mathrm{~m}$ probably had been exposed to a fairly low mean irradiance within the upper $30 \mathrm{~m}$ of the water column.

In order to determine the relative sensitivity to UVR of phytoplankton sampled from various depths, samples were obtained at $5 \mathrm{~m}$, at the base of the UML $(40 \mathrm{~m}$ ) and at $75 \mathrm{~m}$ at Stn UV04 (Fig. 8D). There was a relatively small enhancement of radiocarbon incorporation in the $5 \mathrm{~m}$ samples for both the mylar and plastic treatments ( $12 \%$ and $25 \%$, respectively) and also for the $40 \mathrm{~m}$ samples (20\% and $18 \%$, respectively). The assimilation numbers for the samples from $75 \mathrm{~m}$ were very low, but the values for the mylar and plastic treatments were increased $27 \%$ and $54 \%$, respectively, as compared to the quartz controls (Fig. 8C). Floristic analyses of these samples showed that the percentages (by cell numbers) of flagellates, dinoflagellates, and diatoms in the $5 \mathrm{~m}$ sample were $60 \%, 36 \%$, and $3 \%$, respectively; the corresponding values in the $40 \mathrm{~m}$ sample were $24 \%, 68 \%$, and $7 \%$; in the $75 \mathrm{~m}$ sample they were $68 \%, 23 \%$, and $8 \%$.

At the station nearest the equator (UV07), samples were obtained at $5 \mathrm{~m}$ (within the UML) and at $30 \mathrm{~m}$, which was just below the pycnocline (Fig. $8 \mathrm{~F}$ ). The $5 \mathrm{~m}$
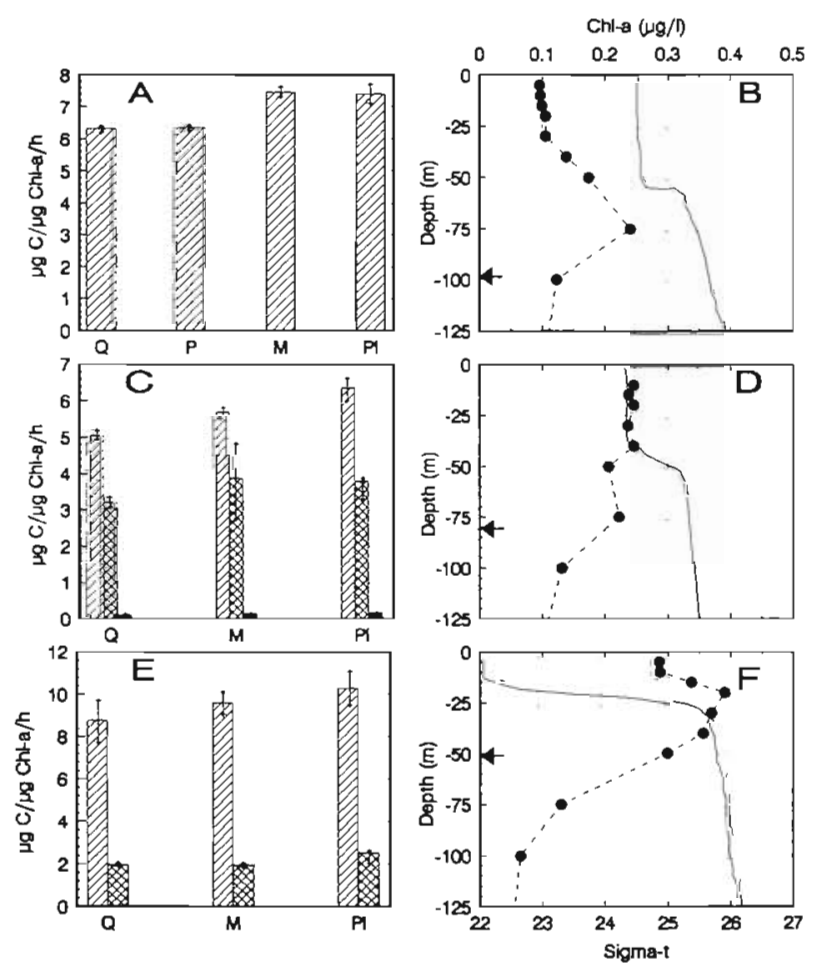

Fig. 8. Effect of different UVR regimes on photosynthetic activity of tropical phytoplankton as affected by the previous irradiation levels to which the cells had been exposed. Data in (A), (C), and (E) show photosynthetic assimilation numbers when samples were exposed to solar radiation filtered through quartz (Q), pyrex (P), mylar (M), and plastic film (Pl). Vertical lines indicate minimum and maximum values. Data in $(B),(D)$, and $(F)$ show the profile of water density (sigma-t) in the upper $125 \mathrm{~m}$; concentrations of chl $a(\bullet---\bullet)$; and depth of $1 \%$ light transmission (arrow). (A), (B) Water sample from $5 \mathrm{~m}$ at station UV01 (March 29, 1991) was incubated with mean PAR of $1807 \mu$ Einsteins $\mathrm{m}^{-2} \mathrm{~s}^{-1}$ and total UVR at local noon of $31 \mathrm{~W} \mathrm{~m}^{-2}$. (C), (D) Water samples from $5 \mathrm{~m}$ (hatched), $40 \mathrm{~m}$ (cross hatched), and $75 \mathrm{~m}$ (black bar) at Stn UV04 (April 1 . 1991), incubated with mean PAR of $2443 \mu$ Einsteins $\mathrm{m}^{-2} \mathrm{~s}^{-1}$ and total UVR at local noon of $38.9 \mathrm{~W} \mathrm{~m}^{-2}$. (E), (F) Water samples from $5 \mathrm{~m}$ (hatched) and $30 \mathrm{~m}$ (cross hatched) at Stn UV07 (April 4, 1991) and incubated with mean PAR of $2759 \mu$ Einsteins $\mathrm{m}^{-2} \mathrm{~s}^{-1}$ and total UVR at local noon of $49.2 \mathrm{~W} \mathrm{~m}^{-2}$ 
samples showed a small enhancement in assimilation numbers for both the mylar and plastic treatments $19 \%$ and $17 \%$, respectively). Assimilation numbers for the $30 \mathrm{~m}$ samples were much lower than those from $5 \mathrm{~m}$ (about 2 as compared to over 8), and the mylar and plastic filters enhanced the values by only $1 \%$ and $28 \%$, respectively (Fig. $8 \mathrm{E}$ ).

At these 3 stations in tropical waters, microscopic observations showed that the phytoplankton crop consisted mainly of nanoplankton. It was dominated by flagellates less than $20 \mu \mathrm{m}$ and naked dinoflagellates which together accounted from 70 to $95 \%$ of the total number of photoautotrophic cells.

\section{Comparison of Antarctic and tropical phytoplankton}

We compared our data on photosynthetic assimilation numbers in our short-term experiments with Antarctic and tropical phytoplankton. In order to have consistency in our comparison of these phytoplankton populations and to minimize the influence of extreme values (i.e. sampies from very different depths), we used only data from samples obtained within the upper mixed layer. Since most experiments had 4 treatments (Quartz, Pyrex, Mylar, and Plastic), we tested the null hypothesis that the mean assimilation numbers of the various treatments were equal:

$$
H_{\mathrm{O}}: \mu_{\mathrm{Q}}=\mu_{\mathrm{P}}=\mu_{\mathrm{M}}=\mu_{\mathrm{Pl}} \text {. }
$$

For the Antarctic phytoplankton an analysis of variance (ANOVA) was done with 132 samples and the test rejected the null hypothesis $(F=38.1 ; \mathrm{p}<0.001)$. Fig. 9A shows the means and the $95 \%$ confidence intervals for each treatment. The mylar and plastic treatments were significantly different than the pyrex
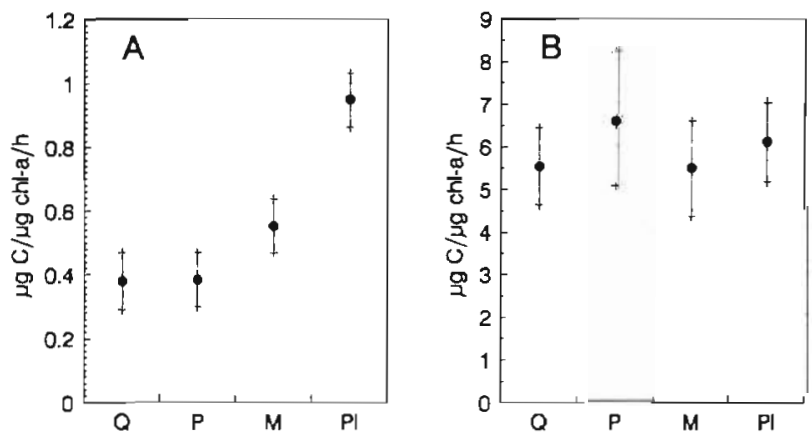

Fig. 9. Comparison of photosynthetic assimilation numbers of Antarctic and tropical phytoplankton when incident solar radiation is filtered through quartz (Q), pyrex (P), mylar (M), or plastic film (Pl). ( $\bullet$ Mean value of all samples; vertical bars: $95 \%$ confidence intervals. (A) Antarctic phytoplankton; total of 132 samples. (B) Tropical phytoplankton; total of 61 samples. All samples were collected within the upper mixed layer and quartz treatments, and also different between themselves (Tukey test).

For the tropical phytoplankton (Fig. 9B) an ANOVA was run for 61 samples and the null hypothesis that the mean assimilation numbers between the 4 treatments (Q. P, M, and Pl) were equal could not be rejected $(F=0.75 ; \mathrm{p}=0.52)$.

\section{DISCUSSION}

It is well known that natural UVR can have many diverse deleterious effects on phytoplankton (Worrest 1983, Döhler 1989, Häder \& Worrest 1991), including decreasing photosynthetic rates (Lorenzen 1979, Smith et al. 1980). With the formation of the ozone hole over Antarctica and the thinning of ozone over the northern hemisphere, serious questions have arisen as to the impact of this enhanced $U V-B$ radiation on aquatic ecosystems. In order to address this problem, it is essential to understand (1) the impact of ambient UVR under normal ozone conditions, (2) the action spectrum for photoinhibition of photosynthesis or for other essential metabolic processes which might be harmed by UVR, (3) changes in incident spectral UVR under reduced ozone concentrations in the stratosphere, and (4) the extent to which phytoplankton can adapt so as to minimize any deleterious effects of increased levels of UVR. Each of these topics is discussed below.

Under the conditions of our experiments it is clear that solar UVR can significantly inhibit rates of photosynthesis of Antarctic marine phytoplankton. By studying the degree of enhancement of photosynthetic rates by removal of certain spectral regions of solar UVR, it is possible to estimate the relative effectiveness of UV$B$ and UV-A, as well as the shorter wavelengths in the UV-B spectral region. Our data indicate that UV-A radiation accounts for over $50 \%$ of the photoinhibition caused by solar UVR, while UV-B radiation accounts for considerably less than $50 \%$ of the total observed UVR effect. The data with samples in pyrex glass vessels show that most of the inhibition of photosynthesis by UV-B radiation is caused by wavelengths greater than $305 \mathrm{~nm}$, as wavelengths less than $305 \mathrm{~nm}$ resulted in relatively small inhibitory effects. Although most reports concerned with harmful effects of UVR emphasize UV-B radiation, there are some reports demonstrating harmful effects of UV-A radiation. Inhibitory effects on photosynthesis by UV-A have been reported (e.g. Hirosawa \& Miyachi 1983), and harmful effects of UV-A have also been demonstrated in animal tissues (Churchill et al, 1991). However, under some conditions, the energy in both UV-B and UV-A spectral regions can also be utilized in photosynthesis (Halldal 1964). 


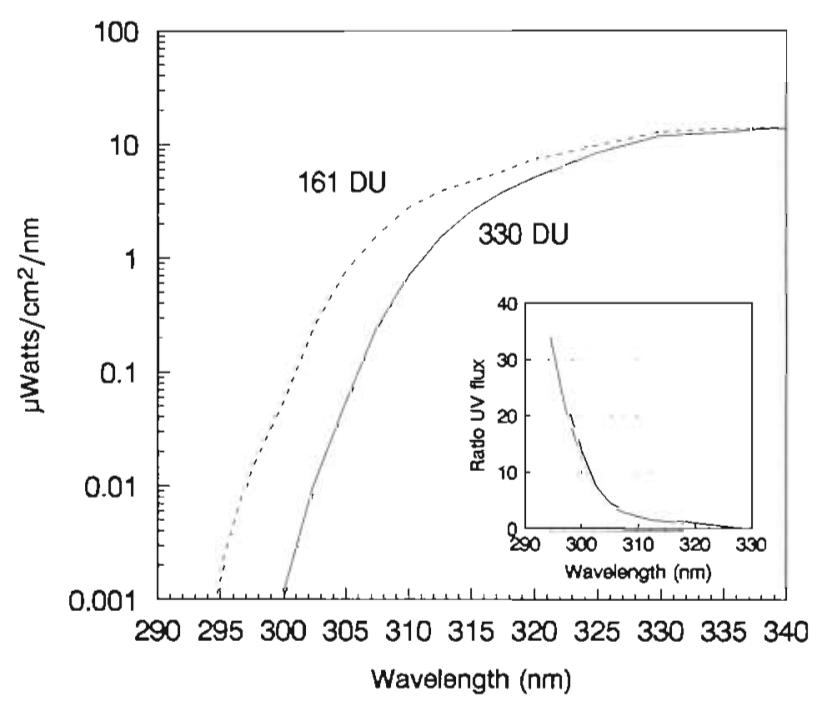

Fig. 10. Spectral UVR irradiance at McMurdo Station in the Antarctic as influenced by ozone concentrations in the atmosphere. (—) Normal UVR measured on October 20, 1989 , with ozone concentration measured at 330 Dobson Units (DU). (-..-) UVR measured on October 20, 1988, with ozone concentration of $161 \mathrm{DU}$, showing enhanced flux of shorter wavelengths in the UV-B portion. Note that ordinate values are on a log scale. Inset: data from 1988 at McMurdo Station showing the ratio of the UV flux on October 8 (ozone $=$ $263 \mathrm{DU}$ ) to the UV flux on October 13 (ozone $=386 \mathrm{DU}$ ). Data from C. R. Booth

The spectral flux of incident solar radiation decreases rapidly below $330 \mathrm{~nm}$ (Fig. 10). Thus, even though UV-A radiation is responsible for most of the inhibition of photosynthetic rates seen in our experiments, the total energy in the spectral band between 323 and $378 \mathrm{~nm}$ is very large (ca $2470 \mu \mathrm{W} \mathrm{cm}{ }^{-2}$ ) compared to that between 295 and $323 \mathrm{~nm}$ (ca $287 \mu \mathrm{W}$ $\mathrm{cm}^{-2}$; data are from measurements on a clear-sky day at 16:00 h on November 21, 1988, at Palmer Station). The ratios of enhancement divided by total energy in 4 spectral bands (Fig. 11A) show that the photoinhibitory effect per unit energy is greatest at the shorter wavelengths. The action spectrum for UVR-induced inhibition of photosynthesis is shown in Fig. 11B, where the lines indicate relative effectiveness as a function of wavelength, with the observed value at $296 \mathrm{~nm}$ being arbitrarily set at 1.0 .

Considering that the effectiveness of UVR for inhibition of photosynthesis increases with the shorter UV-B wavelengths, it might seem that the increased flux of UVR below $305 \mathrm{~nm}$ under the ozone hole (see Fig. 10) might have a very significant impact on decreasing rates of primary production. The energy levels in the spectral region below $300 \mathrm{~nm}$ are so low, however, that it is unlikely that the enhanced levels due to ozone depletion in the atmosphere would have any dramatic impact in short-term $(<1 \mathrm{~d})$ experiments with radio-
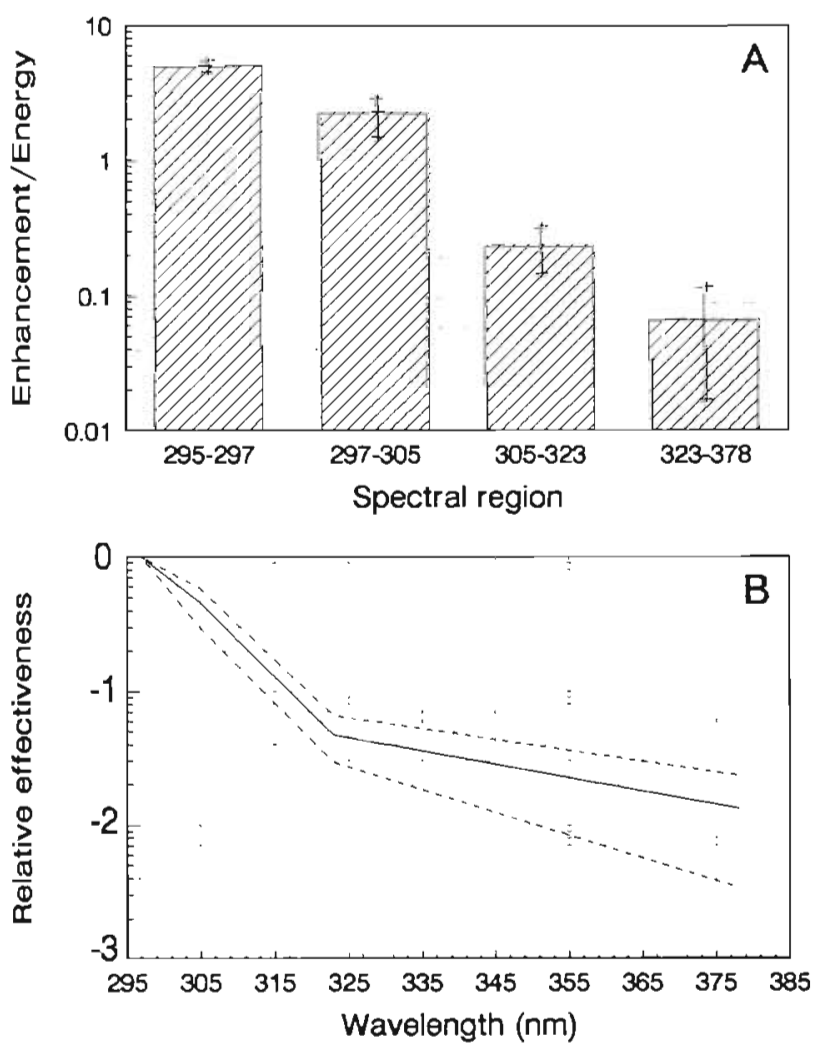

Fig. 11. Estimation of the action spectrum for UVR inhibition of photosynthesis in Antarctic marine phytoplankton by comparison of photosynthetic enhancement results with data on incident spectral irradiance. (A) Each vertical bar shows the ratio of the average percent photosynthetic enhancement resulting from 4 cut-off filters divided by the integrated radiation flux for the spectral regions 295 to 297,297 to 305,305 to 323 , and 323 to $378 \mathrm{~nm}$. Vertical lines indicate minimum and maximum values. (B) Line showing the relative effectiveness of UVR in photoinhibition (expressed as response per unit energy), where the effectiveness is set at 1.0 at $296 \mathrm{~nm}$. Note that the ordinate is a log scale. Dashed lines represent minimum and maximum values

carbon to measure photosynthetic rates. However, we do not know what the primary targets are in regard to UVR-induced depression of photosynthetic rates. The action spectrum shown in Fig. $11 \mathrm{~B}$ has a negative slope, as do the slopes for the general plant response described by Caldwell (1971) and that for DNA damage (Setlow 1974), but it differs appreciably from those 2 action spectra by having much higher effectiveness throughout most of the UVR region. It also differs markedly from action spectra for overall photosynthesis, which have positive slopes with increasing wavelength in the UVR range (Neori et al. 1988). Without knowing what the primary targets are for UVRinduced photoinhibition, we cannot rule out the possibility that the very short UV-B wavelengths (see inset in Fig. 10) might affect rates of primary productivity 
through direct effects on macromolecules such as DNA, which could have a negative feed-back to the photosynthetic capacity of the cell. Such indirect effects, however, might require longer time periods to take effect and hence be missed in one-day experiments.

The only longer-term studies we did with Antarctic phytoplankton were those growth experiments shown in Fig. 6. The cultures in the Antarctic (Fig. 6A) showed no adverse effects of UVR at any time during the $16 \mathrm{~d}$ growth period. However, the mean daily total UVR was about $8 \mathrm{~W} \mathrm{~m}^{-2}$, which is within the threshold range for UVR-induced photoinhibition as suggested by our data in Fig. 5. When this culture was subjected to higher UVR fluences (see Fig. 6D) at low latitudes, dramatic effects were recorded on changes in floristic composition and life-cycle stages, as well as on rates of photosynthesis. A UVR fluence of $8 \mathrm{~W} \mathrm{~m}^{-2}$ represents about 20 to $25 \%$ of incident solar UVR flux recorded during our shipboard operations in the Antarctic, and hence it is likely that this flux of UVR does generate potentially harmful photochemical products. This suggests that celiular DNA repair mechanisms, which include both dark and light processes (Friedberg 1985), can keep pace with the damage rate. If some of the UVR-induced damage to DNA is irreversible, the consequences would be far less serious for unicellular phytoplankton than for multicellular organisms, as the lethal effect would be lost upon death of the daughter cell.

In extrapolating our short-term incubator tests to natural conditions in the water column, it should be noted that our results present a worst-case scenario for 2 major reasons. First, when we attenuate incident solar radiation with neutral density screens, we are not altering the spectral distribution of the radiation incident upon the phytoplankton. When cells are in the water column, the shorter UV-B wavelengths are absorbed relatively quickly as compared to longer wavelengths (Smith \& Baker 1979), so that any cellular damage to organisms at depth should be considerably less than that found in our incubator experiments when normalized to equal flux of PAR. Second, all cells (except perhaps for genetically engineered organisms) have both photo-activated and dark enzymatic processes which can repair or eliminate UVR-initiated structural changes in macromolecules such as DNA (Friedberg 1985). The ability of an organism to survive UVR radiation is thus dependent upon not only the duration and flux of UVR, but the relative ratios of the shorter (damaging) wavelengths to longer wavelengths which are involved in photo-repair mechanisms. In our incubator experiments ratios of various spectral regions were not varied during the course of any one experiment, but were kept as a certain fixed percentage of that in the incident solar radiation. In the normal environment, phytoplankton will be circulating up and down in the UML at a wide range of speeds which may vary from fractions of an hour to hundreds of hours for each circuit (Denman \& Gargett 1983), and hence cells will be continually exposed to variations in total irradiance as well as to spectral concentration of wavelengths toward the 450 to $500 \mathrm{~nm}$ portion of the spectrum. This would tend to minimize cellular damage, as the ratio of energy in UV-B relative to that at UV-A wavelengths would become progressively smaller with depth.

Our results with phytoplankton from tropical waters were very different than the results discussed above for Antarctic populations. Enhancement of photosynthetic rates was relatively small (Fig. 8) and when all samples from within the mixed layer were analyzed together, there were no significant differences in assimilation numbers between any of the spectral regimes used in our experiments (Fig. 9). The assimilation numbers of tropical phytoplankton in the UML

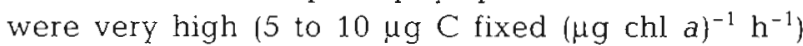
relative to assimilation numbers in the Antarctic (about 0.4 to $3.0 \mu \mathrm{g} \mathrm{C}$ fixed $(\mu \mathrm{g} \mathrm{chl} a)^{-1} \mathrm{~h}^{-1}$ ). These differences are most likely due to different carbon/chi a ratios of the phytoplankton, different species composition of the crop, effects of temperature, and varying nutrient status of the cells. The high assimilation numbers we found in surface tropical waters are consistent with previous data (Kiefer et al. 1976), as are the low assimilation numbers in Antarctic waters (Tilzer et al. 1985, Holm-Hansen \& Mitchell 1991).

Data in Fig. 8 show that when samples are taken from both the top and bottom of the UML (5 and $40 \mathrm{~m}$ ), the assimilation numbers of the 2 samples are fairly comparable, and that the inhibition caused by UVR is about the same in both samples (Fig. 8C). Samples from $75 \mathrm{~m}$, however, showed very low assimilation numbers in all treatments $(0.12$ in quartz to 0.17 when screened with plastic), indicating that these samples were very sensitive to visible radiation (PAR), as has been previously reported (Kiefer et al. 1976). When samples are taken in the UML and just below the pycnocline (Fig. 8F), the assimilation numbers drop by a factor of 4 (which may be related to increased chl a content relative to carbon in the deeper samples), but there is relatively little response to UVR, indicating that these cells are also relatively resistant to UVR. This enhanced tolerance of tropical phytoplankton as compared to Antarctic phytoplankton is similar to that reported by Calkins \& Thordardottir (1980), who worked with various marine and freshwater organisms from ca $63^{\circ} \mathrm{N}$ and ca $36^{\circ} \mathrm{N}$.

Phytoplankton samples from deeper waters in the Antarctic did not seem to be so labile to solar radiation 
as were the tropical phytoplankton from deeper water. Samples from $75 \mathrm{~m}$ (Fig. 4C, D) showed assimilation numbers which were quite normal for the Antarctic $\left(0.5\right.$ to $>1 \mu \mathrm{g} \mathrm{C}$ fixed $\left.(\mu \mathrm{g} \mathrm{chl} a)^{-1} \mathrm{~h}^{-1}\right)$, with screening by mylar and plastic enhancing photosynthetic activity by $40 \%$ and $122 \%$, respectively. Antarctic waters are generally characterized by deep mixing and relatively little change in water density in the upper $100 \mathrm{~m}$ of the water column. Data in Fig. 4B, D \& F, for instance, illustrate representative profiles of water column density, and the difference from the surface to $100 \mathrm{~m}$ depth ranges from 0.25 to 0.50 sigma-t units, whereas in tropical waters the range shown in Fig. 8B, D \& F was from 1.2 to 4.0 sigma-t units. The result of this relative instability of the water column in the southern ocean will be for phytoplankton to circulate in relatively deep UMLs of 40 to $100 \mathrm{~m}$, so that the mean irradiance received by the cells will be fairly low. It is seen that when the UML is $40 \mathrm{~m}$ (Fig. $4 \mathrm{~F}$ ) the chl a concentrations are fairly low, presumably because of light limitation. This is in agreement with recent modelling efforts relating phytoplankton biomass in Antarctic waters to depth and stability of the UML (Mitchell \& HolmHansen 1991). Cells thus will not reside in high-light waters long enough to fully adapt to high solar UVRPAR flux. One station in the Antarctic did have a relatively shallow UML of $20 \mathrm{~m}$ depth (Fig. 4D). Our $15 \mathrm{~m}$ sample at this station showed no inhibition by incident UVR, indicating that these cells had adapted sufficiently so as not to be inhibited by natural irradiation levels of $755 \mu$ Einsteins $\mathrm{m}^{-2} \mathrm{~s}^{-1}$ for PAR and $8.4 \mathrm{~W} \mathrm{~m}^{-2}$ for UVR (mean radiation levels during the incubation period). Previous studies in the Antarctic (Vernet et al. 1989, Karentz et al. 1991b) have demonstrated the capacity for algae to synthesize UV-B protective pigments, as well as the ability to repair UVR-induced damage to DNA by both dark and light repair mechanisms (Karentz et al. 1991a). Whether or not Antarctic species have the capacity to adapt to high light conditions ( $>2000 \mu$ Einsteins $\mathrm{m}^{-2} \mathrm{~s}^{-1}$ ), or to enhanced levels of UV-B resulting from ozone depletion so that they would have the resistance shown by tropical phytoplankton, remains to be seen.

Acknowledgements. This work was supported in part by the National Science Foundation (grants No. DPP88-10462 and DPP-88177635), by NOAA (Cooperative Agreement No. NA90AA-H-AFO20), and by the Alternative Fluorocarbons Environmental Acceptability Study (AFEAS). We thank A. F. Amos for physical oceanographic data, personnel from the Antarctic Marine Living Resources program for general assistance, F. M. H. Reid for help with floristic analyses of preserved samples, B. G. Mitchell and M. Vernet for help with work in the Antarctic, and M. M. Mullin and E. Venrick for comments on the manuscript.

\section{LITERATURE CITED}

Caldwell, M. M. (1971). Solar UV irradiation and the growth and development of higher plants. In: Giese, A. C. (ed.) Photophysiology, Vol. 6. Academic Press, New York, p. 131-177

Calkins, J., Thordardottir, $T$ (1980). The ecological significance of solar UV radiation on aquatic organisms. Nature. Lond. 283: 563-566

Churchill, M. E., Peak, J. G., Peak, M. J. (1991). Correlation between cell survival and DNA single-strand break repair proficiency in the Chinese hamster ovary cell lines AA8 and EM9 irradiated with 365-nm ultraviolet-A radiation. Photochem. Photobiol. 53: 229-236

Denman, K. L., Gargett, A. E. (1983). Time and space scales of vertical mixing and advection of phytoplankton in the upper ocean. Limnol. Oceanogr. 28: 801-815

Döhler, G. (1989). Influence of UV-B (290-320 nm) radiation on photosynthetic ${ }^{14} \mathrm{CO}_{2}$ fixation of Thalassiosira rotula Meunier. Biochem. Physiol. Pfl. 185: 221-226

El-Sayed, S. Z. (1988). Fragile life under the ozone hole. Nat. Hist. 97: 72-80

Farman, J. C., Gardiner, B. G., Shanklin, J. D. (1985). Large losses of total ozone in Antarctica reveal seasonal $\mathrm{ClO}_{\mathrm{x}} / \mathrm{NO}_{\mathrm{x}}$ interaction. Nature, Lond. 315: 207-210

Friedberg, E. C. (1985). DNA repair. W. H. Freeman \& Co., New York

Gribbin, J. (1988). The hole in the sky: man's threat to the ozone layer. Bantam Books, New York

Häder, D-P., Worrest, R. C. (1991). Effects of enhanced solar ultraviolet radiation on aquatic ecosystems. Photochem. Photobiol. 53: 717-725

Halldal, P. (1964). Ultraviolet action spectra of photosynthesis and photosynthetic inhibition in a green and a red alga. Physiol. Plant. 17: 414-421

Hirosawa, T., Miyachi, S. (1983). Effects of long-wavelength ultraviolet (UV-A) radiation on the growth of Anacystis nidulans. Plant Sci. Lett. 28: 291-298

Hitchcock, G. L. (1983). An examination of diatom area volume ratios and their influence on estimates of plasma volume. J. Plankton Res. 5: 311-324

Holm-Hansen, O., Lorenzen, C. J., Holmes, R. W., Strickland, J. D. H. (1965). Fluorometric determination of chlorophyll. J. Cons. perm. int. Explor. Mer 30: 3-15

Holm-Hansen, O., Mitchell, B. G. (1991). Spatial and temporal distribution of phytoplankton and primary production in the western Bransfield Strait region. Deep Sea Res. 38 : 961-980

Holm-Hansen, O., Riemann, B. (1978). Chlorophyll a determination: improvements in methodology. Oikos 30 : 438-447

Karentz, D., Cleaver, J E., Mitchell, D. L. (1991a). Cell survival characteristics and molecular responses of Antarctic phytoplankton to ultraviolet-B radiation. J. Phycol. 27: 326-341

Karentz, D., McEuen, F. S., Land, M. C., Dunlap, W. C. (1991b). Survey of mycosporine-like amino acid compounds in Antarctic marine organisms: potential protection from ultraviolet exposure. Mar. Biol. 108: 157-166

Kiefer, D. A., Olson, R. J., Holm-Hansen, O. (1976). Another look at the nitrite and chlorophyll maxima in the central North Pacific. Deep Sea Res. 23: 1199-1208

Lorenzen, C. J. (1979). Ultraviolet radiation and phytoplankton photosynthesis. Limnol. Oceanogr. 24: 1117-1120

Lubin, D., Frederick, J. E. (1991). The ultraviolet radiation environment of the antarctic peninsula: The roles of ozone and cloud cover. J appl. Meteorol. 30: 478-493 
Lubin, D., Frederick, J. E., Booth, C. R., Lucas, T., Neuschuler, D. (1989). Measurements of enhanced springtime ultraviolet radiation at Palmer Station, Antarctica. Geophys. Res. Lett. 16: 783-785

Mitchell, B. G., Holm-Hansen, O. (1991). Observations and modelling of the Antarctic phytoplankton crop in relation to mixing depth. Deep Sea Res. 38: 981-1007

Neori, A., Vernet, M., Holm-Hansen, O., Haxo, F. T. (1988). Comparison of chlorophyll far-red and red fluorescence excitation spectra with photosynthetic oxygen action spectra for photosystem II in algae. Mar. Ecol. Prog. Ser. 44: $297-302$

Newman, P., Stolarski, R., Schoeberl, M., McPeters, R., Krueger, A. (1991). The 1990 Antarctic ozone hole as observed by TOMS. Geophys. Res. Lett. 18: 661-664

Reid, F. M. H. (1983). Biomass estimation of components of the marine nanoplankton and picoplankton by the Utermöhl settling technique. J. Plankton Res. 5: 235-252

Setlow, R. B. (1974). The wavelengths in sunlight effective in producing skin cancer. A theoretical analysis. Proc. natn. Acad. Sci. USA 71: 3363-3366

Smith, R. C., Baker, K. S. (1979). Penetration of UV-B and biologically effective dose-rates in natural waters. Photochem. Photobiol. 29: 311-323

Smith, R. C., Baker, K. S., Holm-Hansen, O., Olson, R. J.

This article was submitted to the editor
(1980). Photoinhibition of photosynthesis in natural waters. Photochem. Photobiol. 31: 585-592

Stolarski, R. S., Bloomfield, P., McPeters, R. D., Herman, J. R. (1991). Total ozone trends deduced from Nimbus 7 TOMS data. Geophys. Res. Lett. 18: 1015-1018

Strathmann, R. R. (1967). Estimating the organic carbon content of phytoplankton from cell volume or plasma volume. Limnol. Oceanogr. 12: 411-418

Tilzer, M. M., Bodungen, B. v., Smetacek, V. (1985). Lightdependence of phytoplankton photosynthesis in the Antarctic Ocean: implications for regulating productivity. In: Siegfried, W. R., Condy, P. R., Laws, R. M. (eds.) Antarctic nutrient cycles and food webs. Springer-Verlag, Berlin, p. 60-69

Utermöhl, H. (1958). Zur Vervollkommnung der quantitativen Phytoplankton-Methodik. Mitt. int. Verein. Limnol. 9: $1-38$

Vernet, M., Mitchell, B. G., Holm-Hansen, O. (1989). UV radiation in Antarctic waters: response of phytoplankton pigments. Antarct. J. U.S. 24: 181-183

Voytek, M. A. (1989). Ominous future under the ozone hole. Environmental Defense Fund, Washington, D.C.

Worrest, R. C. (1983). Impact of solar uitraviolet-B radiation (290-320 nm) upon marine microalgae. Physiol. Plant. 58: $428-434$

Manuscript first received: September 24, 1991

Revised version accepted: December 17, 1991 